\title{
Perancangan Spiral Kondensor untuk Pengolahan Sampah Plastik Menjadi Bahan Bakar Minyak dengan Proses Pirolisis
}

\author{
(Design of Spiral Condenser for Processing Plastic Waste \\ into Oil Fuel by Pyrolysis Process) \\ Moh Arif Batutah ${ }^{1 *}$, Deni Arifin ${ }^{2}$, Poniman $^{3}$, dan Solikin ${ }^{4}$ \\ 1,2,3,4 Program Studi Teknik Mesin, Fakultas Teknik, Universitas Muhammadiyah Surabaya \\ Jl. Sutorejo No. 59 Surabaya, Jawa Timur 60113
}

\section{ARTICLE INFO}

Article history

Received : 10 Agustus 2021

Revised : 11 September 2021

Accepted : 22 September 2021

DOI :

https://doi.org/10.33366/rekabua na.v6i2.2686

Keywords : fuel; plastic waste; spiral condenser

*e-mail corresponding author : arifbatutah@ft.um-surabaya.ac.id

\section{ABSTRAK}

Penelitian ini bertujuan untuk mengetahui dimensi kondensor alur spiral untuk merubah sampah plastik menjadi bahan bakar minyak, untuk mengetahui efektifitas bahan pembuatan kondensor alur spiral. Penelitian ini dilakukan dengan tahapan : identifikasi potensi, pengumpulan data, desain peralatan dan perhitungan, validasi desain, pengujian dan uji kelayakan alat. Pada proses pengujian dan uji kelayakan alat yaitu dengan memasukkan sampah plastik kedalam reaktor proses pirolisis, selanjutnya dipanaskan sampai temperatur $180{ }^{\circ} \mathrm{C}$ dan terjadi proses penguapan, uap yang yang diperoleh selanjutnya di kondensasi menjadi bahan bakar minyak. Rancangan kondensor alur spiral yang telah dibuat dengan panjang $3 \mathrm{~m}$, berdiameter $30 \mathrm{~cm}$ dan tinggi $34 \mathrm{~cm}$ menggunakan bahan besi galfanis $1 / 2$ inch dan tebal plat $0.0127 \mathrm{~mm}$, proses sirkulasi air pendingin menggunakan pipa besi spiral, dengan suhu uap yang masuk ke dalam kondensor $180{ }^{\circ} \mathrm{C}$ dan temperatur air pada kondensor $40{ }^{\circ} \mathrm{C}$. dari $1000 \mathrm{gr}$ sampah plastik dapat dihasilkan sebanyak $100 \mathrm{ml}$ bahan bakar minyak.
\end{abstract}

\section{PENERBIT}

\section{UNITRI PRESS}

Jl. Telagawarna, TlogomasMalang, 65144, Telp/Fax: 0341-565500

\section{(a) (1) (-)}

This is an open access article under the Creative Commons Attribution-ShareAlike 4.0 International License. Any further distribution of this work must maintain attribution to the author(s) and the title of the work, journal citation and DOI. CC-BY-SA

\section{ABSTRACT}

This study aims to determine the dimensions of the spiral groove condenser to convert plastic waste into fuel and determine the material's effectiveness for making spiral groove condensers. This research was conducted in stages: potential identification, data collection, equipment design and calculation, design validation, testing, and equipment feasibility test. In the testing and equipment feasibility test, namely by inserting plastic waste into the pyrolysis process reactor, then heated to a temperature of $180{ }^{\circ} \mathrm{C}$ and an evaporation process occurs, the vapors obtained are then condensed to be fuel. The spiral groove condenser design is made with a length of $3 \mathrm{~m}$, a diameter of $30 \mathrm{~cm}$, and a height of $34 \mathrm{~cm}$ use $1 / 2$ inch galvanized iron material and a plate thickness of $0.0127 \mathrm{~mm}$. The cooling water circulation process uses a spiral iron pipe, with a temperature of steam entering the condenser $180{ }^{\circ} \mathrm{C}$ and the temperature of the water in the condenser is 40 ${ }^{\circ} \mathrm{C}$. From $1000 \mathrm{gr}$ of plastic waste can be produced as much as $100 \mathrm{ml}$ of fuel.

Cara Mengutip : Batutah, M. A., Arifin, D., Poniman, P., Solikin, S. (2021). Perancangan Spiral Kondensor untuk Sipil dan Teknik Kimia, 6(2), 174-183. doi:https://doi.org/10.33366/rekabuana.v6i2.2686 


\section{PENDAHULUAN}

Plastik merupakan salah satu komoditas yang telah begitu luas digunakan dan disebut sebagai salah satu inovasi terbesar dalam era millennium, plastik bersifat ringan, harganya murah, fleksibel dan tidak berkarat, sehingga pemanfaatan plastik secara global semakin meningkat setiap tahun [1]. Plastik bekas akan dibuang ke lingkungan dan mencemari lingkungan karena sifat plastik sulit terdegradasi. Oleh karena itu, beberapa alternatif yang telah di kembangkan untuk mengolah sampah plastik yang efektif, seperti pemanfaatan sampah plastik menjadi bahan bakar [2].

Cadangan bahan bakar dunia semakin menipis di saat dunia masih tergantung pada bahan bakar fosil. Kekhawatiran bahan bakar fosil yang semakin lama menipis untuk kepentingan tersebut, saatnya menggunakan bahan bakar terbarukan berupa pemanfaatan sampah plastik menjadi bahan bakar, dengan melakukan peroses pirolisis [3]. Hal ini di lakukan pada dasarnya plastik berasal dari minyak bumi, selain itu plastik mempunyai nilai kalor cukup tinggi, setara bahan bakar fosil dan solar, dengan cara melakukan proses peyulingan distalasi [4].

Beberapa penelitian sebelumnya diantaranya dilakukan oleh Setiawan dkk., (2021)., Mursito., dkk (2017), [5]-[7], mereka melakukan penelitian tentang distilasi pengolahan sampah plastik menjadi bahan bakar minyak menggunakan kondensor bertingkat dan pendingin kompresi uap. Hasil penelitian peralatan distilasi telah dapat menghasilkan kondesat berupa bahan bakar minyak, dengan pembakaran sampah plastik, bahan bakar minyak yang di hasilkan belum terindentifikasi secara kimiawi, sementara Das dan Pande (2007), Arwizet (2017) [8], [9], melakukan penelitian pemanfatkan sampah plastik menjadi bahan bakar minyak dengan pendinginan kondensor alur spiral. Metode yang digunakan adalah proses pirolisis sampah plastik dengan uap panas yang dihasilkan selanjutnya dikondensasi melalui kondensor alur spiral.

Adapun tujuan penelitian ini adalah untuk mengetahui cara pemanfaatan sampah plastik menjadi bahan bakar minyak dan untuk mengetahui efektifitas bahan pembuatan kondensor alur spiral yang lebih sederhana dibandingkan dengan peneliti-peneliti sebelumnya, sehingga manfaat dari penelitian ini antara lain terciptanya bahan bakar minyak terbarukan sebagai energi alternatif, mengurangi sampah plastik, sebagai sarana alternatif untuk penanganan masalah sampah plastik pada lingkungan, meningkatkan nilai ekonomi dari sampah sampah plastik dan terciptanya peralatan kondensor alur spiral yang lebih sederhana untuk proses kondensasi proses pirolisis sampah plastik.

\section{METODE PENELITIAN}

Metode penelitian berisi rancangan penelitian untuk memperoleh data yang diinginkan dan pengerjaan dengan urutan pelaksanaan percobaan sebagai berikut :

1. Identifikasi potensi dan masalah : mengidentifikasi potensi dan masalah yang terjadi untuk mengetahui dimensi kondensor agar efektif dalam menghasilkan bahan bakar minyak. 
2. Pengumpulan data atau informasi : pengumpulan data dan informasi sebagai acuan perencanaan alat, dengan cara observasi beberapa data mengenai efektifitas pipa spiral dalam pendinginan.

3. Desain produk : desain produk ini meliputi persiapan alat dan bahan, mempersiapakan semua alat dan bahan yang dibutuhkan dalam penelitian dan perancangan alat

4. Validasi desain oleh ahli atau yang berkompeten, validasi desain adalah kegiatan untuk menilai secara perhitungan dan rasional.

5. Revisi desain : setelah dilakukan validasi alat maka dapat diketahui kekurangannya. Jika alat hasil desain mengalami kegagalan, maka perlu dilakukan perbaikan atau redesain ulang.

6. Pengujian atau uji coba alat : peralatan dilakukan uji coba agar tidak terjadi kesalahan dan berfungsi sesuai dengan perancangan. Pengujian dilakukan setelah semua proses pembuatan alat selesai, jika ada kesalahan atau kekurangan kerja pada alat tersebut, maka dilakukan perbaikan, pengujian sistem tekan dan pengujian gaya dorong maupun tarik dilakukan.

7. Analisa kerja alat atau uji kelayakan alat : uji kelayakan alat dilakukan untuk memastikan bahwa peralatan hasil perancangan layak dioperasikan, tidak ada keretakan, kebocoran dan lain-lain, uji kelayakan dilakukan dengan cara memanaskan air yang dimasukkan ke dalam sistem peralatan sampai mendidih dan terkondensasi. Proses pirolisis sampah plastik dengan memasukkan sampah plastik pada reaktor distilasi (A), kemudian dipanaskan pada sampai temperatur $180{ }^{\circ} \mathrm{C}$ sebagaimana terbaca pada temperatur indikator (D), lalu dikondensasikan menggunakan kondensor alur spiral (B), media pendingin menggunakan air yang disirkulasikan dari tangki air (C) sebagaimana pada Gambar 1 dan Gambar 2 berikut :

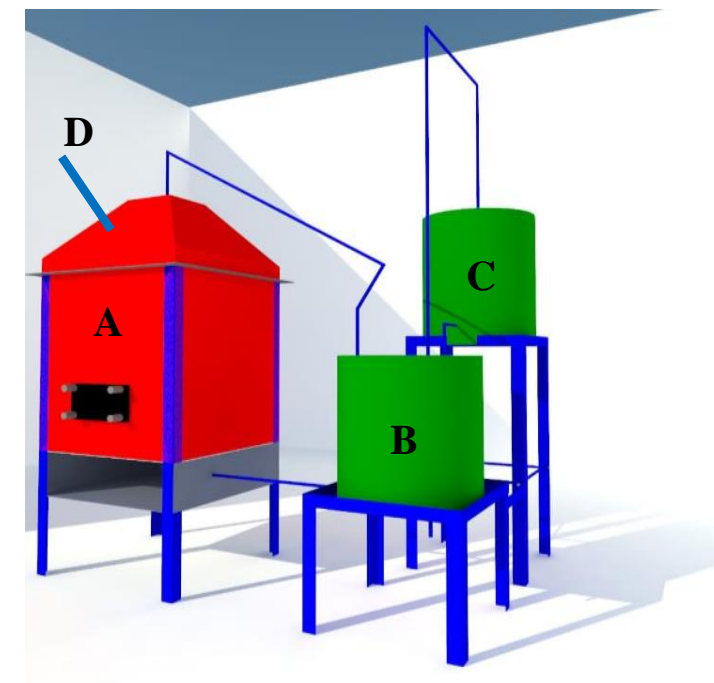

Gambar 1. Rencana desain peralatan proses pirolisis sampah plastik, (A) reaktor distilasi, (B) kondensor pipa alur spiral, (C) tanki air pendingin, (D) temperatur indikator.

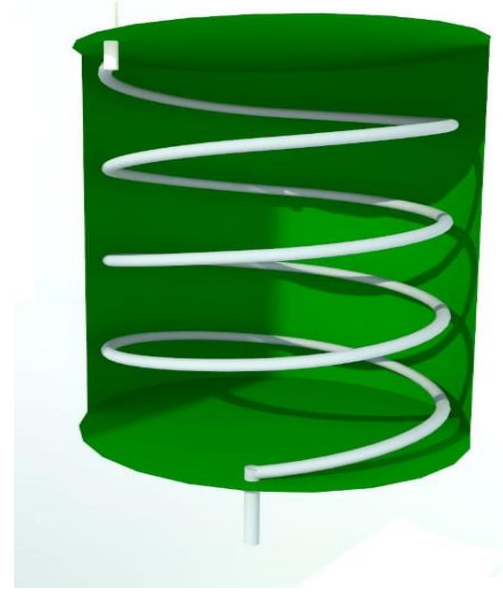

Gambar 2. Rencana desain kondensor pipa alur spiral 


\section{HASIL DAN PEMBAHASAN}

Pada pembuatan kondensor alur spiral di gunakan 1 (satu) drum bekas yang mudah di dapatkan dan cepat dalam pembuatannya, selanjutnya pipa dengan panjang 3 meter dibentuk menjadi 3 (tiga) spiral dengan diameter lingkaran $10 \mathrm{~cm}$, dengan alat pengerol pipa. Fungsi pipa spiral untuk mengalirkan uap panas yang berasal dari reaktor proses pirolisis, sedangkan air yang akan mendinginkan uap panas pada kondensor alur spiral berasal dari tanki air yang di sirkulasi dengan pompa. Untuk memasukan pipa spiral sendiri perlu memotong bagian atas drum dan menutup kembali dengan cara pengelasan dan memberi pipa aliran pada drum menuju tanki penampung yang berfungsi untuk sirkulasi pendinginan pada uap yang ada pada pipa spiral.

Dengan temperatur mencapai $100{ }^{\circ} \mathrm{C}, 160{ }^{\circ} \mathrm{C}$ dan $180{ }^{\circ} \mathrm{C}$ uap dari reaktor proses pirolisis yang dihasilkan selanjutnya dikondensasikan, tanki air yang berisi air pendingin bertujuan untuk mensirkulasi agar terjadi proses kondensasi uap, hasil kondensasi menghasilkan bahan bakar minyak. Hasil rancangan dari alat kondensor alur spiral dapat dilihat pada Gambar 3 dan Gambar 4 sebagai berikut :

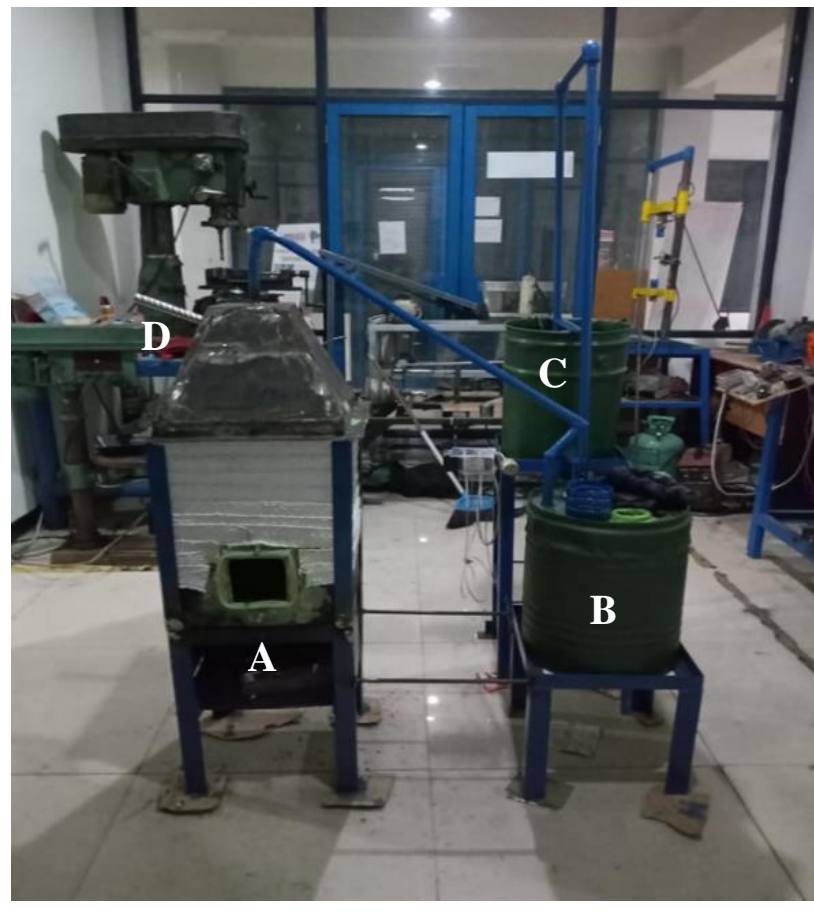

Gambar 3. Peralatan proses pirolisis sampah plastik, (A) reaktor distilasi, (B) kondensor pipa alur spiral, (C) tanki air pendingin, (D) temperatur indikator.

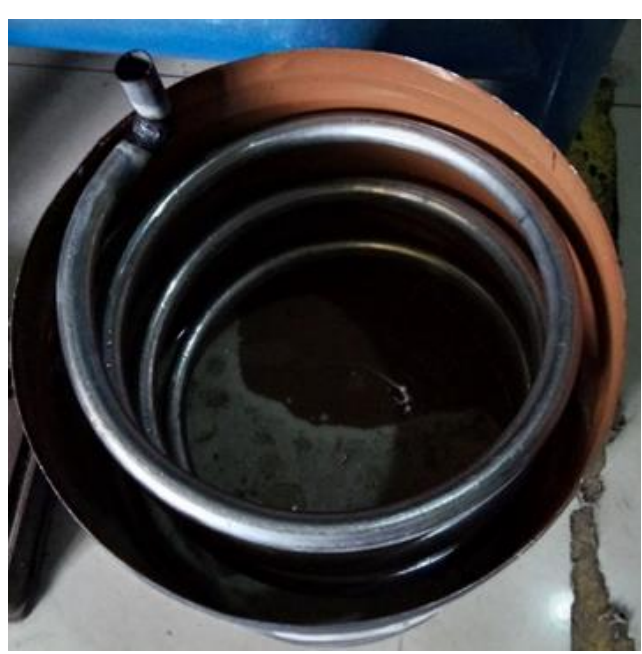

Gambar 4. Pipa kondensor Spiral hasil rancangan

Proses pembuatan peralatan kondensor Gambar 3 dan 4 terlebih dahulu melakukan perhitungan - perhitungan, berikut adalah hasil proses pirolisis menggunakan peralatan Gambar 3 dengan 3 variasi suhu pemanasan sebagimana pada Tabel 1 berikut : 
Tabel 1. Hasil proses pirolisis sampah plastik jenis polypropilane.

\begin{tabular}{ccccccc}
\hline $\begin{array}{c}\text { Berat } \\
\text { plastik } \\
(\mathrm{gr})\end{array}$ & $\begin{array}{c}\text { Temperatur } \\
\text { pemanasan } \\
\left({ }^{\mathrm{O}} \mathrm{C}\right)\end{array}$ & $\begin{array}{c}\text { Air } \\
\text { pendingin } \\
(\text { liter })\end{array}$ & $\begin{array}{c}\text { Jumlah } \\
\text { distilat } \\
(\mathrm{ml})\end{array}$ & $\begin{array}{c}\text { Berat } \\
\text { ampas } \\
(\mathrm{gr})\end{array}$ & $\begin{array}{c}\text { Waktu } \\
\text { pemanasan } \\
(\text { menit })\end{array}$ & $\begin{array}{c}\text { Massa gas } \\
\text { LPG } \\
(\mathrm{gr})\end{array}$ \\
\hline 1.000 & 100 & 19 & 20 & 500 & 90 & 175 \\
1.000 & 160 & 19 & 40 & 350 & 90 & 210 \\
1.000 & 180 & 19 & 100 & 250 & 90 & 250 \\
\hline
\end{tabular}

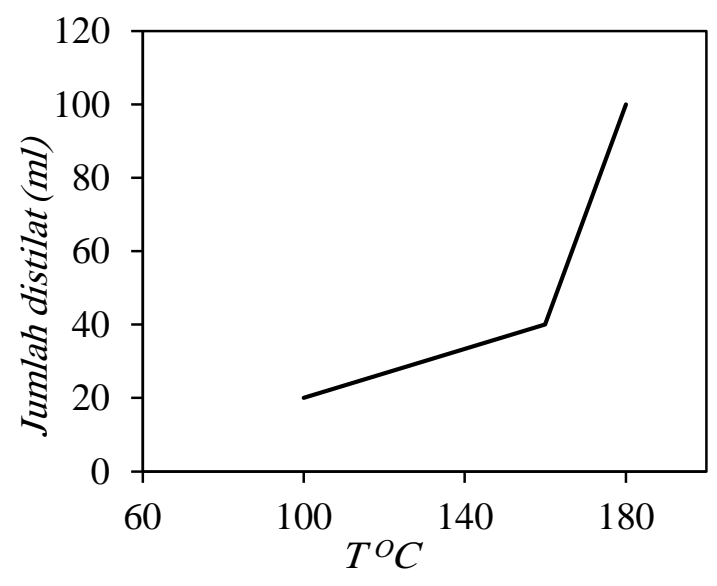

Gambar 5. Grafik hasil data distilat

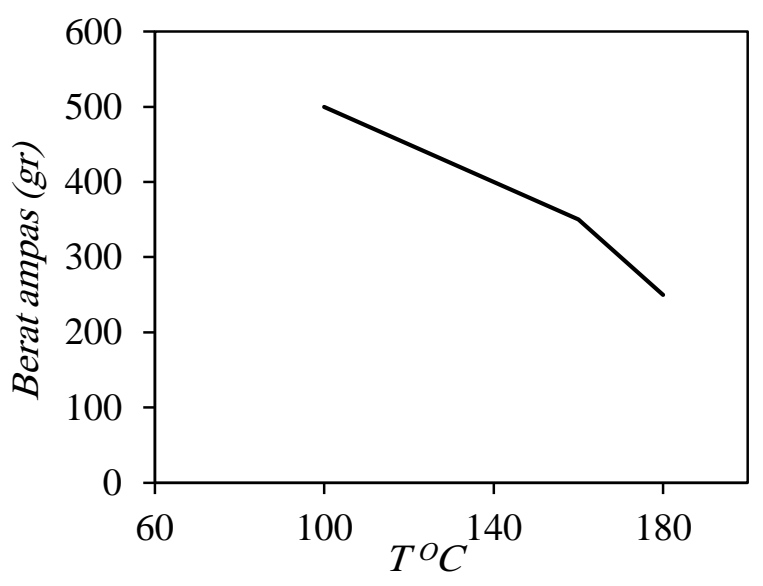

Gambar 6. Grafik hasil data berat ampas

Gambar 5 menunjukkan jumlah distilat bahan bakar minyak yang diperoleh pada temperatur $100{ }^{\circ} \mathrm{C}$ menghasilkan $20 \mathrm{ml}$, temperatur $160{ }^{\circ} \mathrm{C}$ menghasilkan $40 \mathrm{ml}$ dan temperatur $180{ }^{\circ} \mathrm{C}$ mengasilkan $100 \mathrm{ml}$, semakin tinggi temperatur yang di gunakan semakin tinggi perolehan hasil distilat,. Hal ini menunjukkan bahwa temperatur sangat berpengaruh terhadap hasil distilat yang diperoleh.

Sedangkan pada Gambar 6 menunjukkan bahwa semakin rendah suhu proses pirolisis, ampas yang di hasilkan lebih besar sebagaimana terlihat pada Tabel 1 , temperatur $100{ }^{\circ} \mathrm{C}$ menghasilkan ampas $500 \mathrm{gr}$, temperatur $160{ }^{\circ} \mathrm{C}$ menghasilkan $350 \mathrm{gr}$ ampas dan temperatur $180{ }^{\circ} \mathrm{C}$ menghasilkan $250 \mathrm{gr}$ ampas sisa proses pirolisis, dari gambar tersebut menunjukkan bahwa proses pirolisis sampah plastik menjadi bahan bakar cair semakin optimal di temperatur yang lebih tinggi dibandingkan dengan temperatur yang lebih rendah.

\section{Pengambilan Data Perhitungan Daya Burner}

Untuk mengetahui jumlah energy dari burner yang dipakai untuk melakukan proses pirolisis sampah plastik menjadi bahan bakar minyak sesuai dengan temperatur yang ingin dicapai, bisa dihitung dengan mengetahui massa gas LPG yang dipakai dan nilai kalor dari gas LPG dengan low heating velue atau LHV LPG sebesar $46.110 \mathrm{~J} / \mathrm{gr}$, massa gas LPG yang terpakai $(m) 250$ gr dan $t$ waktu pemanasan 90 menit, maka fuel consumtion $(F c)$ dihitung dengan persamaan (1) sebagai berikut [10] : 


$$
\begin{aligned}
F_{C} & =\frac{m(g r) \times \operatorname{LHV}\left(\frac{\mathrm{J}}{g r}\right)}{t(\text { menit })} \\
F_{C} & =\frac{250 \times 46.110}{90 \text { menit }}=\frac{11,527 \mathrm{kj}}{90 \mathrm{menit}} \\
& =128 \mathrm{kj} / \text { menit }
\end{aligned}
$$

\section{Daya Pompa}

Pompa yang dipakai untuk mengalirkan air pendingin ke tabung kondensor pada saat proses pengujian alat distilasi menggunakan pompa dengan spesifikasi tegangan $(V) 220$ volt, arus (I) 3,5 ampher dengan persamaan (2) berikut :

$$
\rho=V . I
$$

dimana $\rho=$ density cairan $\left(\mathrm{kg} / \mathrm{m}^{3}\right), V$ sebagai kecepatan rata-rata aliran $(\mathrm{m} / \mathrm{s})$ dan $I$ adalah arus listrik ( $\mathrm{m} / \mathrm{s})$ [11], maka dengan persamaan (2) dalam waktu 2 jam didapatkan nilai daya $1.540 \mathrm{Watt}$

\section{Efisiensi Distilasi}

Untuk mengetahui perbandingan jumlah (kuantitas) minyak yang didapatkan dari proses pirolisis maka bisa dilakukan dengan persamaan (3) berikut ini :

Efisiensi distilat $(\%)=\frac{(\text { Berat awal }(\mathrm{kg}))-\text { Berat residu }(\mathrm{kg}))}{\text { Berat basah }} \times 100 \%$

Sehingga didapatkan efisiensi distilat pada temperatur $180{ }^{\circ} \mathrm{C}$ sebesar $50 \%$, temperatur $160{ }^{\circ} \mathrm{C}$ sebesar $35 \%$ sedangkan temperatur $100{ }^{\circ} \mathrm{C}$ sebesar $25 \%$

\section{Efisiensi Teknis}

Efisiensi teknis alat distilasi agar mengetahui persen perbandingan energy yang dipakai atau digunakan pada saat proses distilasi menggunakan persamaan (4) sebagai berikut :

$$
\text { Efisiensi teknis }=\frac{\text { massa destilat } . \text { Nilai kalor destilat }}{\text { massagas } . \text { NK gas }+ \text { Daya pompa }} \chi 100 \%
$$

dari persamaan (4) didapatkan efesiensi teknis pada temperatur $100{ }^{\circ} \mathrm{C}$ sebesar $15 \%$, temperatur $160{ }^{\circ} \mathrm{C}$ sebesar $17 \%$ dan pada temperatur $180{ }^{\circ} \mathrm{C}$ sebesar $22 \%$, hal ini menunjukkan bahwa semakin tinggi temperatur efisiensi teknis semakin baik, jadi hubungan antara efisiensi teknis dengan efisiensi distilasi menunjukkan bahwa energi yang dipakai pada saat proses distilasi memiliki prosentase yang lebih banyak dibandingkan dengan energi yang dapat dihasilkan, dalam hal ini hubungannya yaitu hasil minyak distilasi yang didapat dari proses pirolisis. 
Tabel 2. Hubungan temperatur dengan ampas yang dihasilkan dan efisiensi proses pirolisis sampah plastik

\begin{tabular}{ccccc}
\hline $\begin{array}{c}\text { Berat plastik } \\
(\mathrm{gr})\end{array}$ & $\begin{array}{c}\text { Temperatur } \\
\left({ }^{\circ} \mathrm{C}\right)\end{array}$ & Berat ampas (gr) & $\begin{array}{c}\text { Efisiensi teknis } \\
(\%)\end{array}$ & $\begin{array}{c}\text { Efisiensi } \\
\text { distilasi }(\%)\end{array}$ \\
\hline 1000 & 100 & 500 & 15 & 25 \\
1000 & 160 & 350 & 17 & 35 \\
1000 & 180 & 250 & 22 & 50 \\
\hline
\end{tabular}

\section{Kapasitas Laju Produksi Alat Distilasi}

Kapasitas laju produksi [11] menunjukan jumlah minyak yang didapat dari proses pirolisis sampah plastik menjadi bahan bakar minyak, dihitung dengan persamaan (5) berikut :

$$
\mathrm{Q}=\frac{W}{t}=\frac{100 \mathrm{gr}}{1,8}=55.5 \mathrm{gr} / \mathrm{jam}
$$

Gambar 7 menunjukkan bahwa semakin tinggi temperatur proses pirolisis, semakin besar pula gas LPG yang dibutuhkan untuk pemrosesan. Sedangkan pada Gambar 8 terlihat bahwa hasil data efisiensi teknis dengan perolehan tertinggi pada temperatur $180{ }^{\circ} \mathrm{C}$ menghasilkan 22\%, hal ini menunjukkan bahwa semakin tinggi temperatur yang di gunakan semakin tinggi efisiensi teknis yang diperoleh.

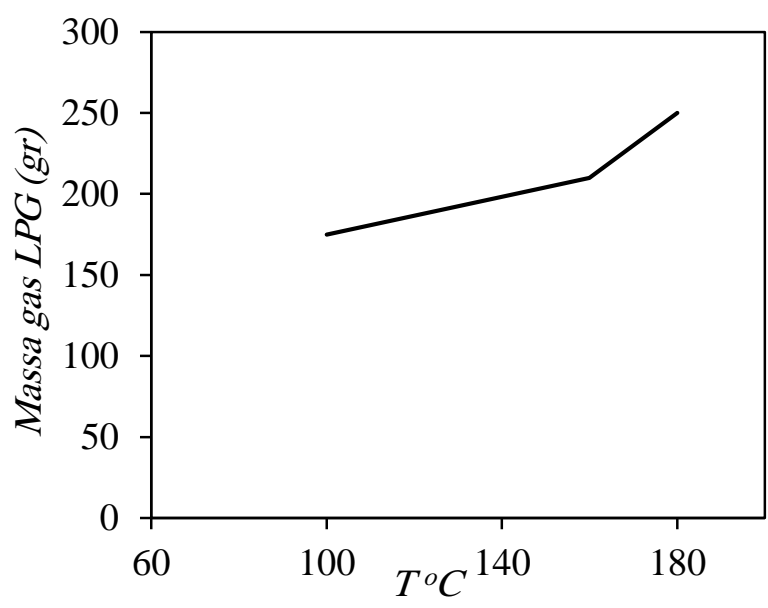

Gambar 7. Grafik hasil data massa gas LPG yang dipakai percobaan.

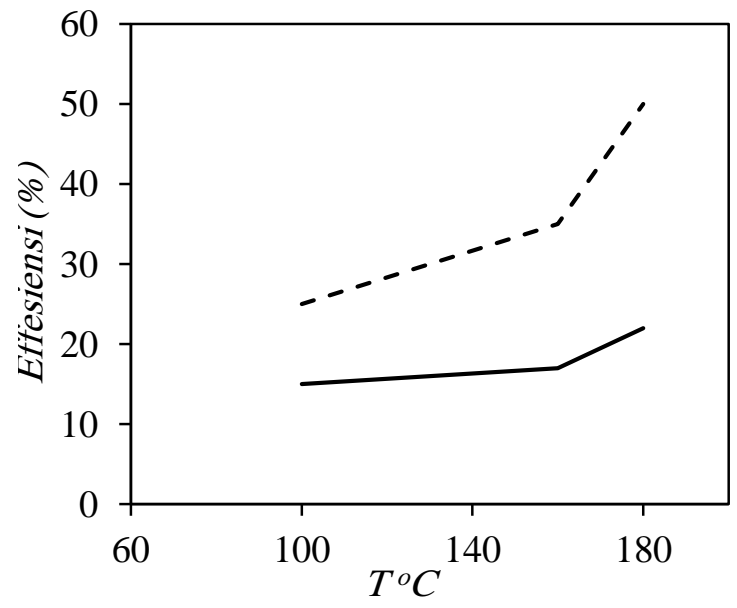

Gambar 8. Grafik hasil data efisiensi distilasi dan efisiensi teknis, (--) ; efisiensi teknis, (- - -) ; effisiensi distilasi.

Gambar 8 juga menunjukan perolehan tertinggi efesiensi distilasi pada temperatur 180 ${ }^{\circ} \mathrm{C}$ sebesar $50 \%$, selain itu efisiensi distilasi juga lebih besar dibandingkan dengan effisiensi teknis.

\section{Desain Kondensor}

Setelah mendapatkan temperatur uap yang melalui $T_{i}$ kondensor misalnya $120{ }^{\circ} \mathrm{C}$, suhu air yang masuk dalam kondensor $25{ }^{\circ} \mathrm{C}$, suhu permukan pipa $T_{o}$ sebesar $35{ }^{\circ} \mathrm{C}$, dengan pipa bersih berdiameter luar $=0.014 \mathrm{~m}$, diameter dalam $=0.01143 \mathrm{~m}$ dan diameter luar 
$=0.0127 \mathrm{~m}$, sehingga suhu film dapat dihitung dengan persamaan (6), Holman (1986.) [10] :

$$
\begin{aligned}
& T_{\mathrm{f}}=\frac{T i+T o}{2} \\
& T_{\mathrm{f}}=\frac{120+35}{2}=77^{\circ} \mathrm{C}
\end{aligned}
$$

Koefesien panas $(h)$ dalam $\mathrm{W} / \mathrm{m}^{\circ} \mathrm{C} .[10]$ dapat dihitung dengan persamaan (7) :

$$
\mathrm{h}=0,725\left[\frac{p(p-p v) \times g \times h f g \times k}{\mu \times d \times(T g-T u)}\right]
$$

dimana $p$ densitas $\left(\mathrm{kg} / \mathrm{m}^{3}\right), g$ gravitasi $\left(\mathrm{m} / \mathrm{s}^{2}\right), h_{f g}$ evaporasi entalpi $(\mathrm{kJ} / \mathrm{kg}), \mu$ viskositas dinamik $(\mathrm{kg} / \mathrm{ms}), T g$ suhu saturasi dan $T w$ suhu di dinding, maka didapatkan nilai koefesien panas $(h)$ sebesar $88.39 \mathrm{~W} / \mathrm{m} .{ }^{\mathrm{O}} \mathrm{C}$.

Perpindahan panas konduksi dalam kondensor dihitung dengan persamaan (8) berikut :

$$
\mathrm{q}=\frac{\ln \left(\frac{r o}{r i}\right)}{2 \pi k l(T i-T o)}
$$

dimana $q$ perpindahan panas secara konduksi (joule), $\mathrm{r}_{\mathrm{i}}$ jari-jari dalam pipa $(\mathrm{m}), \mathrm{r}_{\mathrm{o}}$ jarijari luar pipa (m), $l$ panjang pipa $(\mathrm{m}), \mathrm{k}$ konduktivitas panas $(\mathrm{watt} / \mathrm{m} K)$ dan $\left(T_{i}-T_{o}\right)$ perbedaan pipa luar dan pipa $(K)[10]$, dengan persamaan (9).

Konveksi bagian luar pipa kondensor, suhu film $T_{\mathrm{f}}=\frac{35+25}{2}=30^{\circ} \mathrm{C}$, pada bagian luar kondensor terjadi konveksi luar paksa seperti pers (9) maka :

$$
R e=\frac{\mu \cdot D}{v}
$$

dimana $R e$ bilangan renold, $\mu$ viskositas dinamik $(\mathrm{m} / \mathrm{s}), v$ kecepatan aliran bebas $(\mathrm{m} / \mathrm{s}), D \quad$ diameter pipa (m) [10].

$$
\operatorname{Re}=\frac{u . D}{v}=\frac{0.625 \cdot 0,0127}{0,0037}=23,794
$$

Maka aliran yang terjadi pada kondensor adalah Turbulen dimana aliran yang terjadi didalam kondensor adalah aliran crossflow pada Cylinder maka nilai $N U_{c y l}$ persamaan (10) sebagai berikut :

$$
N U_{c y l}=\mathrm{C} \cdot R e, \operatorname{Pr}^{n}
$$

dimana $\mathrm{Nu}$ Nusselt number / bilangan Nusselt, C konstanta, Re bilangan Reynold, Pr bilangan Prandtl, sehingga bilangan Nusselt di dapatkan 7,712 [10], sedangkan koefesien ho dihitung oleh pers (11) dibawah ini :

$$
h_{o}=\mathrm{k} \frac{N u}{D}
$$

dimana $k$ konduktivitas thermal, $N u$ bilangan Nusselt, $D$ diameter pipa, sehingga ho = $0,456 \mathrm{~W} / \mathrm{m}^{\circ} \mathrm{C}$ 
Nilai dari overall Heat Teransfer Coefficient [10], dihitung dengan pers (12) berikut :

$$
U_{O}=\frac{1}{\frac{i d}{o d} \times \frac{I}{h} \times \frac{i d(i d / o d)}{2 \times \pi \times K} \times \frac{I}{h o}}
$$

dimana $U_{O}$ nilai overall, id diameter dalam, od diameter luar, $K$ konstanta, $h$ koefisien perpindahan panas dan ho koefisien konveksi aliran diluar tube didapatkan nilai $U o$ sebesar $251,98 \mathrm{~W} / \mathrm{m} .{ }^{\circ} \mathrm{C}$

Jika nilai dari overall heat transfer coefficient maka ditentukan panjang kondensor yang dibutuhkan untuk mengkondensasikan gas hasil pirolisis plastik Panjang kondensor yang dibutuhkan, oleh karena itu perlu mengetahui $\triangle L M T D$ (Logarithmic Mean Temperature Difference) atau rata - rata temperatur dalam proses di kondensor [10] dengan pers (13) berikut :

$$
\triangle T L M T D=\frac{\left(T_{2}-t_{1}\right)-\left(T_{2}-t 1\right)}{\ln \frac{\left(T^{1}-t_{2}\right)}{\left(T^{2}-t_{1}\right)}}
$$

$\triangle L M T D$ untuk aliran yang berlawanan yang masuk (counter flow), $T_{1}$ temperatur fluida panas masuk, $T_{2}$ temperatur fluida panas keluar, $t_{1}$ temperatur fluida dingin masuk, $t_{2}$ temperatur fluida dingin keluar, nilai $\triangle L M T D$ sebesar $126,08^{\circ} \mathrm{C}$

Jika nilai temperatur rata-rata menyeluruh kondensor $126,08^{\circ} \mathrm{C}$ maka luas permukan dinding [10] yang di perlukan dihitung dengan pers (14) :

$$
A=\frac{q}{\text { Uo. } \triangle \text { LMTD }}
$$

Dimana $A$ luas permukan dinding, $q$ perpindahan panas, $U_{o}$ nilai overall, maka nial $A$ $=0,0197 \mathrm{~m}^{2}$. jika diameter luar pipa kondensor adalah $0,0127 \mathrm{~m}$ maka panjang pipa kondensor [10] yang di perlukan dengan persamaan (15) :

$$
\mathrm{L}=\frac{A}{i d}
$$

dimana $L$ panjang pipa kondensor, $A$ luas permukan dinding, $i d$ diameter dalam, maka didapatkan $3 \mathrm{~m}$.

\section{KESIMPULAN}

Berdasarkan dari hasil perancangan pembuatan kondensor alur spiral untuk pirolisis sampah plastik menjadi bahan bakar minyak di atas dapat disimpulkan bahwa rancangan yang telah dibuat dengan kondensor alur spiral dengan panjang pipa $3 \mathrm{~m}$, berdiameter 30 $\mathrm{cm}$ dan tinggi drum $34 \mathrm{~cm}$ menggunakan bahan besi galvanis $1 / 2$ inch dan tebal plat 0.0127 $\mathrm{mm}$, proses sirkulasi pendinginan menggunakan pipa besi spiral, dengan suhu uap yang masuk ke dalam kondensor $180{ }^{\circ} \mathrm{C}$ dan suhu air pada kondensor $40{ }^{\circ} \mathrm{C}$, dari $1000 \mathrm{gr}$ sampah plastik dapat dihasilkan sebanyak $100 \mathrm{ml}$ bahan bakar minyak, dimana bahan bakar minyak yang dihasilkan belum dilakukan analisa komposisi kimiawi. 


\section{PENGHARGAAN}

Penulis mengucapkan banyak terimaksih kepada Lembaga Penelitian dan Pengabdian Masyarakat (LPPM), Universitas Muhammadiyah Surabaya yang telah membiayai penelitian ini dengan Nomer Kontrak No : 01/II.3.AU/LPPM/F/2021

\section{DAFTAR PUSTAKA}

[1] R. Thahir, "Sintesa Bahan Bakar Berbasis Ramah Lingkungan Dengan Metode Pirolisis Thermal Dan Catalytic Cracking Dari Limbah Plastik," Institut Teknologi Sepuluh Nopember, 2019.

[2] U. B. Surono, "Berbagai Metode Konversi Sampah Plastik Menjadi Bahan Bakar Minyak,” J. Univ. Janabadra Yogyakarta, vol. 3, no. 1, pp. 31-34, 2013.

[3] T. T. Sharobem, Tertiary Recycling Of Waste Plastics: An Assesment Of Pyrolysis By Microwave Radiation. New York: Columbia University.

[4] S. Haryadi, "Pengaruh Arah Aliran Air Pendingin Pada Kondensor Terhadap Hasil Pengembunan Proses Pirolisis Limbah Plastik," Fak. Tek. Univ. Negeri Semarang, p. $92,2015$.

[5] D. Setiawan and D. Irawan, "Analisa Pipa Alur Spiral Pada Alat Penyuling Bioetanol," Turbo J. Progr. Stud. Tek. Mesin, vol. 1, no. 2, pp. 42445-42454, 2012 , doi: $10.24127 /$ trb.v1i2.654.

[6] Mursito and Judhid Adi, "Perancangan dan Pengujian Alat Destilasi Minyak Dari Limbah Sampah Plastik,” Tek. Desain Mek., vol. 6, no. 4, pp. 311-317, 2017.

[7] S. Das and S. Paney, "Pyrolysis and Catalytic Cracking of Municipal Plastic Waste for Recovery of Gasoline Range Hydrocarbons Pyrolysis and Catalytic Cracking of Municipal Plastic Waste for Recovery of Gasoline Range Hydrocarbons," Thesis Natl. Inst. Technol. Rourkela, pp. 10-55, 2007.

[8] A. Arwizet, "Mesin Destilasi Pengolahan Sampah Plastik Menjadi Bahan Bakar Minyak Menggunakan Kondensor Bertingkat Dan Pendingin Kompresi Uap," INVOTEK J. Inov. Vokasional dan Teknol., vol. 17, no. 2, pp. 75-88, 2017, doi: 10.24036/invotek.v17i2.34.

[9] J. Arifin and S. Ihsan, "Analisa Dan Perancangan Limbah Plastik Sampah Polyethylene Terephthalate Untuk Menghasilkan Bahan Bakar Alternatif," J. EEICT (Electric, Electron., vol. 1, no. 1, pp. 53-60, 2018.

[10] J. P. Holman, Heat Transfer, Sixth edit. New York: McGraw Hill Ltd., 1986.

[11] Munson, B. R, D. F. Young, and T. H. Okiishi., Mekanika Fluida. Jakarta: Erlangga, 2005. 